\title{
Wspomnienia
}




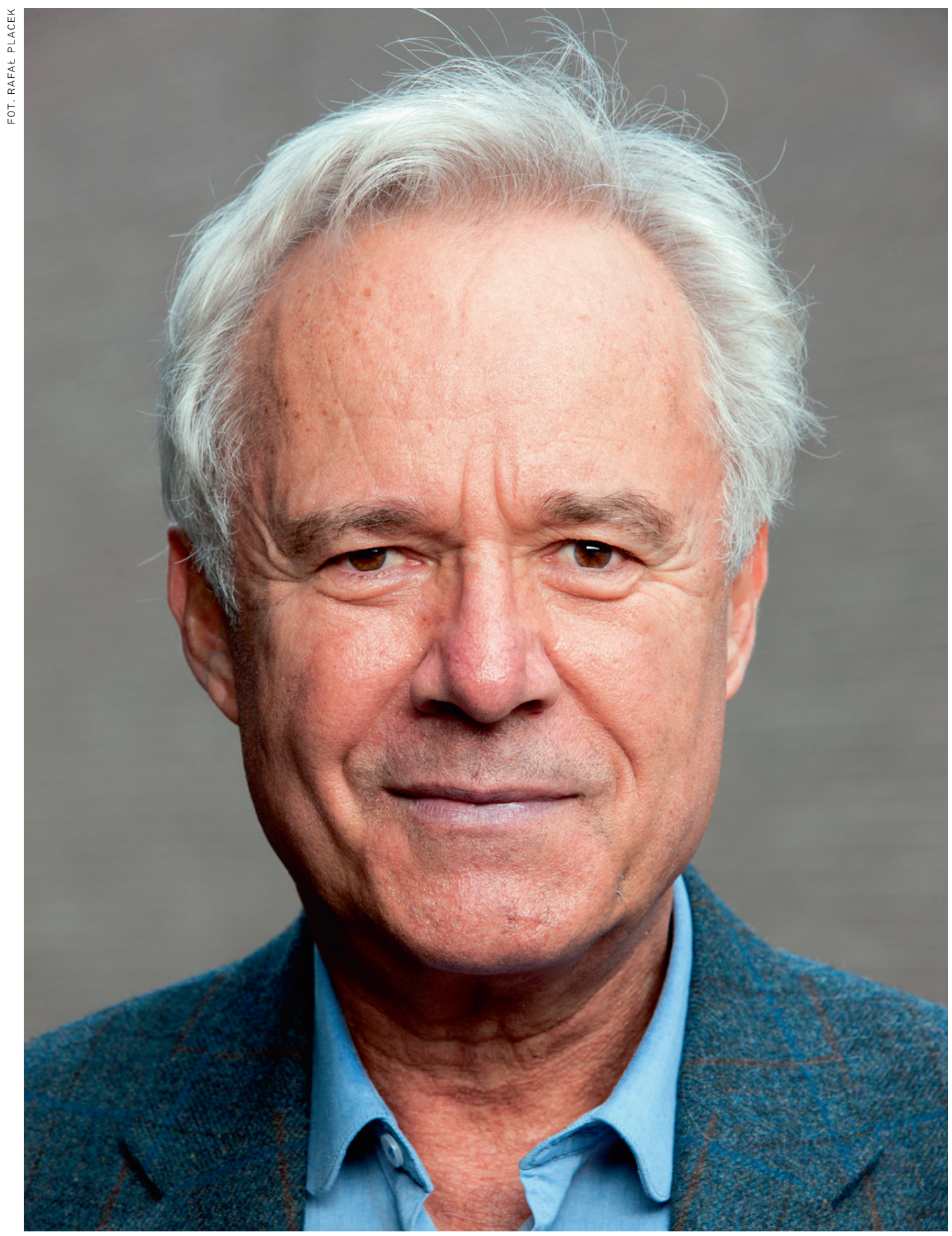

Jerzy Limon

(OARCHIWUMGTS 


\section{Jacek Fabiszak}

Uniwersytet im. Adama Mickiewicza w Poznaniu

ORCID: 0000-0003-3369-og1X

\section{Małgorzata Grzegorzewska}

\section{Magia teatru}

\section{Wspomnienie o Profesorze Jerzym Limonie (1950-2021)}

Powiedzieć, że Profesor Jerzy Limon był człowiekiem renesansu, to nic nie powiedzieć, ale to wciąż nieprecyzyjne określenie przychodzi do głowy każdemu, kto zetknął się z nim osobiście lub poprzez jego liczne publikacje, wystąpienia konferencyjne, zajęcia czy wywiady w mediach. To właśnie przez niezwykłą pracowitość i intensywną obecność Profesora jego brak jest tak odczuwalny i dotkliwy. Wybitny naukowiec, znawca Shakespeare'a, teatru, literatury angielskiej, nauczyciel akademicki, który wykształcił pokolenia anglistów, tłumacz, prozaik, twórca i dyrektor Festiwalu Szekspirowskiego 


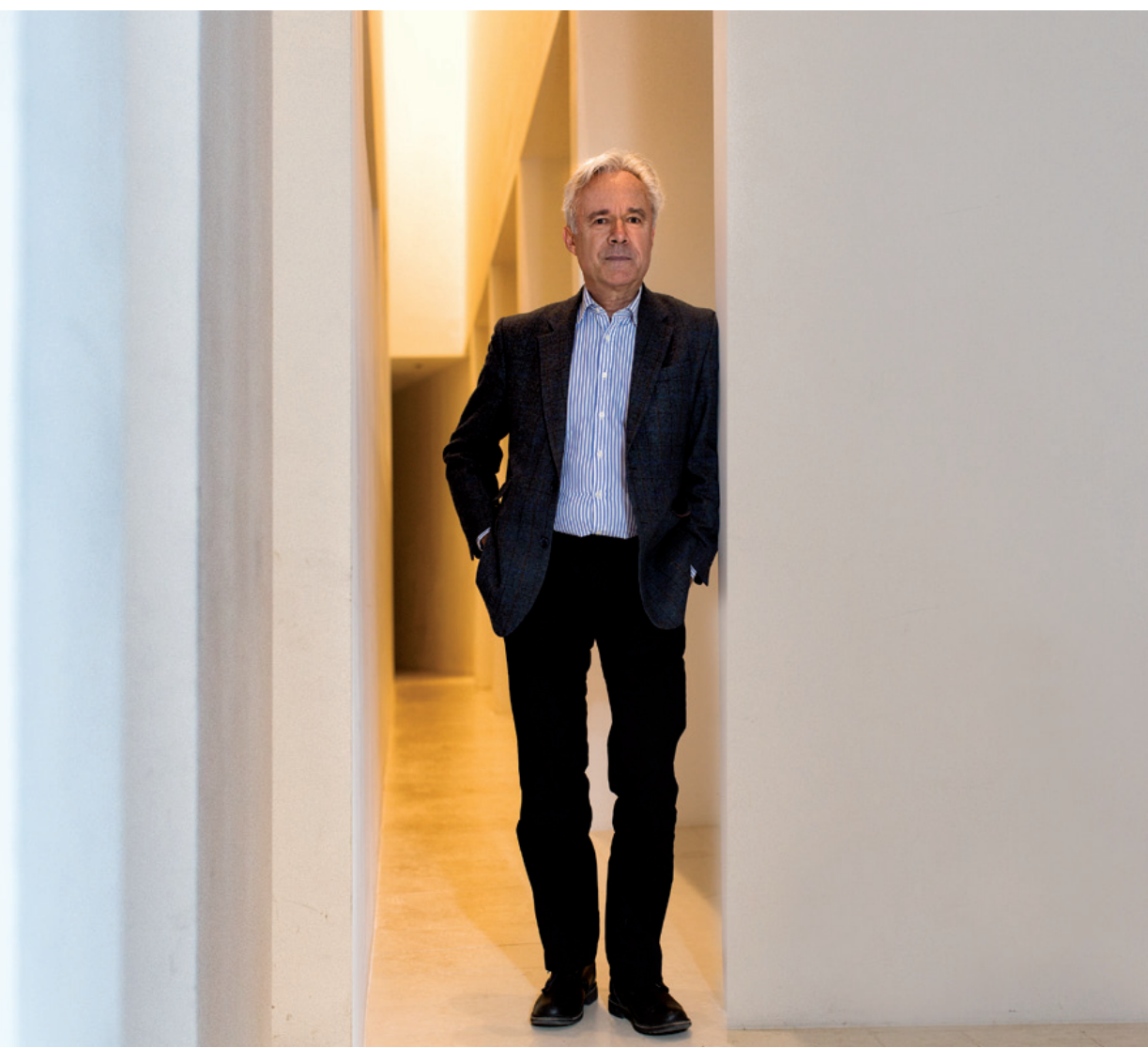

Jerzy Limon w Gdańskim Teatrze Szekspirowskim

i Gdańskiego Teatru Szekspirowskiego, był postacią niezastąpioną. Trudno wyobrazić sobie współczesną szekspirologię i teatrologię, Gdańsk, Polskę i świat bez Profesora Limona.

Jerzy Limon całe swoje życie związany był z Wybrzeżem, z Gdańskiem i ukochanym Sopotem, choć szlify naukowe zdobywał w Poznaniu - tutaj ukończył studia w Instytucie Filologii Angielskiej na Uniwersytecie im. Adama Mickiewicza, tutaj także się doktoryzował. Habilitację i tytuł profesora otrzymał na Uniwersytecie Gdańskim, którego stał się prawdziwą podporą i jednym z najznamienitszych luminarzy. Gdańsk jest także miejscem, któremu Profesor Limon przywrócił Shakespeare’a i które rozsławił na świecie dzięki Shakespeare’owi. Odkrył bowiem, że na początku XVII wieku w Gdańsku występowali angielscy wędrowni aktorzy, którzy, dogadawszy się z mieszczanami, osiedli tam i regularnie grali 
w budynku nazywanym Szkołą Fechtunku, co zostało opisane między innymi w Gdańskim teatrze „elżbietańskim”. To właśnie badania nad tym unikatowym zjawiskiem teatralnym przyniosły Jerzemu Limonowi międzynarodową sławę i uznanie. O randze tego odkrycia niech świadczy anegdota, którą opowiedział kiedyś profesor Henryk Zbierski, promotor jego doktoratu. Kiedy w 1977 ukazał się w „Pamiętniku Teatralnym” artykuł Limona o teatrze renesansowym w Gdańsku², w świecie anglosaskim zawrzało i „kserokopiarki były rozgrzane do czerwoności”, kopiując - przypomnijmy - napisany po polsku tekst!

W 1985 w prestiżowym wydawnictwie Cambridge University Press Jerzy Limon wydał ważną monografię Gentlemen of a Company: English Players in Central and Eastern Europe 1590-166033, szczegółowo i rzetelnie przedstawiającą losy angielskich aktorów, którzy - nie mogąc znaleźć pracy w rodzimej Anglii - ruszyli „za chlebem" do kontynentalnej Europy i trafili między innymi do Gdańska, Elbląga i Królewca, a także do Czech i Austrii. Dzięki dociekaniom Limona świat dowiedział się o tych niezwykle ważnych, a zupełnie nieznanych związkach kulturowych pomiędzy teatralną Anglią a Europą.

Rok później wychodzi kolejna monografia Jerzego Limona, tym razem poświęcona, jak wskazuje tytuł, niebezpiecznym związkom polityczno-dramatycznym za schyłkowych rządów króla Jakuba I4, które autor - dzięki wielkiej wiedzy i kulturze naukowej - odkrywa i przekonująco interpretuje. Jego następna książka - The Masque of Stuart Culture ${ }^{5}$ - jest również poświęcona dramatowi i teatrowi siedemnastowiecznej Anglii. Maska dworska stanowiła nieco zaniedbane pole badań i można śmiało powiedzieć, że dzięki tej publikacji w świecie nauki wzrosło zainteresowanie ciekawym i słabo rozpoznanym tematem. Wnikliwe czytanie tekstów kultury szesnasto- i siedemnastowiecznej charakteryzuje także ostatnią książkę Profesora Szekspir bez cenzury: Erotyczny żart na scenie elżbietańskiej ${ }^{6}$.

Innym polem badawczym z powodzeniem uprawianym przez Jerzego Limona stała się refleksja teoretyczna nad teatrem i jego unikatowością. Jej wyjątkowość i nowatorski charakter zasadza się na podkreślaniu istoty czasu w doświadczeniu teatralnym i próbie naukowego ujęcia zjawiska gry aktorskiej. W swoich badaniach nie ograniczał się do sceny tradycyjnej - stworzył kompletne, teoretyczne

\footnotetext{
1 Jerzy Limon, Gdański teatr „elżbietański”(Wrocław: Zakład Narodowy im. Ossolińskich, 1989).

2 Jerzy Limon, „Przypuszczalne związki teatru gdańskiej «Szkoły Fechtunku» z teatrem «Fortune» w Londynie”, Pamiętnik Teatralny 26, z. 1 (1977): 29-39.

3 Jerzy Limon, Gentlemen of a Company: English Players in Central and Eastern Europe 1590-166o (Cambridge: Cambridge University Press, 1985).

4 Jerzy Limon, Dangerous Matter: English Drama and Politics in 1623-1624 (Cambridge: Cambridge University Press, 1986).

5 Jerzy Limon, The Masque of Stuart Culture (Newark: University of Delaware Press, 1990).

6 Jerzy Limon, Szekspir bez cenzury: Erotyczny żart na scenie elżbietańskiej (Gdańsk: Fundacja Terytoria Książki, 2018).
} 
opracowania teatru radiowego i teatru telewizji. Teoretyczny namysł nad teatrem zawarł w licznych artykułach oraz książkach: Między niebem a sceną: Przestrzeń $i$ czas $w$ teatrze ${ }^{7}$, Trzy teatry: Scena, telewizja, radio ${ }^{8}$, Piaty wymiar teatru ${ }^{9}$, Obroty przestrzeni: Teatr telewizji - próba ujęcia teoretycznego $o^{10}$, Brzmienia czasu: O aktorstwie i mowie scenicznej" oraz anglojęzycznej The Chemistry of the Theatre: Performativity of Time ${ }^{12}$. Z przekornym uśmiechem zadawał często studentom zagadki, których celem było uwrażliwienie odbiorcy na umowność komunikacji w teatrze. „W jakim języku mówią postaci w Burzy Shakespeare’a?” - pytał. Każdy wie, że sztuka została napisana w języku angielskim; na scenach całego świata wystawia się ją w przekładach; postaci są obywatelami Neapolu i Mediolanu... Kiedy odpowiadający bezskutecznie starał się rozplątać ten węzeł, Profesor cierpliwie tłumaczył, że język w dramacie wystawianym na scenie jest znakiem języka, którym opisujemy otaczającą nas rzeczywistość i posługujemy się w komunikacji z innymi. W ten sposób uczył zrozumienia zaczarowanego świata teatru, w którym język, czas i przestrzeń ulegają przedziwnym przemianom.

Jerzy Limon był także, o czym czasem się zapomina, utalentowanym pisarzem. Formalnie jego prozę można określić jako niezwykle erudycyjną wariację na temat postmodernistycznej fikcji. Akcję swoich opowiadań i powieści często umiejscawiał na Kaszubach. Jest autorem takich utworów, jak Münchhauseniada ${ }^{13}$, Kaszubska Madonna ${ }^{14}$, Wieloryb ${ }^{15}$, Koncert Wielkiej Niedźwiedzicy: Kantata na jedna ulicę, siedem gwiazd i dwa głosy ${ }^{16} \mathrm{czy}$ Młot na poetów albo Kronika ściętych głów ${ }^{17}$. Jego teksty urzekają subtelnością wyobraźni i pięknem języka, a wiedza historyczna autora budzi podziw.

Pasję naukową i literacką łączył Jerzy Limon na jednym jeszcze polu: tłumaczeń. Dał się tutaj poznać nie tylko jako tłumacz tekstów renesansowych, Szekspirowskich, sięgał także po współczesny dramat. Wspólnie z Władysławem Zawistowskim przełożył Tragedię Hoffmana Chettle’a ${ }^{18}$, Troilusa i Kressydę ${ }^{19}$ oraz

\footnotetext{
7 Jerzy Limon, Między niebem a sceną: Przestrzeń i czas w teatrze (Gdańsk: słowo/obraz terytoria, 2002).

8 Jerzy Limon, Trzy teatry: Scena, telewizja, radio (Gdańsk: słowo/obraz terytoria, 2003).

9 Jerzy Limon, Piąty wymiar teatru(Gdańsk: słowo/obraz terytoria, 2006).

10 Jerzy Limon, Obroty przestrzeni: Teatr telewizji - próba ujęcia teoretycznego (Gdańsk: słowo/obraz terytoria, 2008).

11 Jerzy Limon, Brzmienia czasu: 0 aktorstwie i mowie scenicznej (Gdańsk: słowo/obraz terytoria, 2011).

12 Jerzy Limon, The Chemistry of the Theatre: Performativity of Time (New York: Palgrave Macmillian, 2010).

13 Jerzy Limon, Münchhauseniada (Poznań: Wydawnictwo Poznańskie, 1980).

14 Jerzy Limon, Kaszubska Madonna (Gdańsk: Graf, 1991).

15 Helena Szymańska [Jerzy Limon], Wieloryb: Wypisy źródłowe (Gdańsk: „Tower Press”, 1998).

16 Jerzy Limon, Koncert Wielkiej Niedźwiedzicy: Kantata na jednq̨ ulicę, siedem gwiazd i dwa głosy (Warszawa: „Twój Styl”, 1999).

17 Jerzy Limon, Młot na poetów albo Kronika ściętych głów (Gdańsk: Fundacja Terytoria Książki, 2014).

18 Henry Chettle, Tragedia Hoffmana albo Zemsta za ojca, tłum. Jerzy Limon i Władysław Zawistowski, wstęp i przypisy Jerzy Limon (Gdańsk: Wydawnictwo Morskie, 1985)

19 William Shakespeare, Trojlus i Kressyda, tłum. i posł. Jerzy Limon i Władysław Zawistowski (Gdańsk: Graf, 1990).
} 
Antoniusza i Kleopatrę ${ }^{20}$ Shakespeare'a, a samodzielnie sztuki Toma Stopparda: Prawdziwy inspektor Hound ${ }^{21}$ i Artysta schodzący po schodach ${ }^{22}$. Wielu czytelników pamięta na pewno jego tłumaczenie scenariusza filmu Zakochany Szekspir pióra Toma Stopparda i Marca Normana, opatrzone fachowym komentarzem, który przybliża czytelnikowi i widzowi zawiłości kulturowe świata Shakespeare’a ${ }^{23}$. Drążył znaczenie pojedynczych słów i przy każdej okazji wskazywał na obecne w oryginale misterne kalambury, jak choćby ukryte w słowach Makbeta wezwanie, by żona dawała mu tylko synów lub... rodziła zbroje (takie były w czasach Shakespeare'a dwa znaczenia słowa male). Dbał o zrozumienie tekstu i piękno przekładu w czasach, kiedy - jak ze smutkiem skonstatował odbierając Nagrodę im. Gieysztora - „język trochę sparszywiał”. Nie zgadzał się na bycie osaczonym "przez pustosłowie, słowa-wydmuszki” ${ }^{24}$.

Profesor Limon swoją fascynację teatrem i Shakespeare'em połączył w działalności o bardziej praktycznym i artystycznym charakterze, sprawiając, że sztuki Stradfordczyka „wróciły” do Gdańska. Najpierw utworzył Fundację Theatrum Gedanense, której celem było (od)budowanie teatru elżbietańskiego w Gdańsku. Fundacja rozpoczęła działalność między innymi od zorganizowania Dni Szekspirowskich, podczas których pokazywano spektakle teatralne. W 1997 miała miejsce inauguracja Festiwalu Szekspirowskiego, który uczynił z Gdańska (i całego Trójmiasta) miejsce „pielgrzymek” teatromanów i miłośników Shakespeare’a z Polski i całego świata. Festiwal jest niezwykle bogatym przedsięwzięciem: oprócz nurtu głównego, można zobaczyć eksperymentalne przedstawienia w ramach Szekspiroff, organizowane są prelekcje i wystawy, wręczana jest nagroda Złotego Yoricka za najlepszy polski spektakl szekspirowski. Festiwal odbywa się regularnie co roku, w 2021 planowana jest jego dwudziesta piąta edycja. Bez założyciela i dyrektora...

W 2008 nastąpił kolejny wielki krok na drodze ku budowie teatru: powołano instytucję Gdański Teatr Szekspirowski, która nadzorowała powstawanie, a teraz od 2014 - zarządza teatrem. Jej dyrektorem został oczywiście Jerzy Limon. Teatr, stojący w miejscu dawnej Szkoły Fechtunku, nie jest repliką swojej poprzedniczki; zaskakuje śmiałą architekturą. Historia splata się tu z nowoczesnością. Uroczyste rozpoczęcie budowy w 2011 roku upamiętnił „balet maszyn”: wspaniałe widowisko, którego gwiazdami były ogromne koparki. Przestrzeń w obrębie murów stanowi osobliwy, ciemny labirynt przypominający wąskie uliczki średniowiecznego

\footnotetext{
20 William Shakespeare, Antoniusz i Kleopatra, tłum. Jerzy Limon i Władysław Zawistowski (Gdańsk: „Tower Press”, 200o).

21 Tom Stoppard, „Prawdziwy inspektor Hound”, tłum. Jerzy Limon, Teatr, nr 10-11 (2003): 50-67.

22 Tom Stoppard, Artysta schodzący po schodach, tłum. Jerzy Limon (Warszawa: Wydawnictwo TR, 2003).

23 Marc Norman i Tom Stoppard, Zakochany Szekspir, tłum., wstęp i komentarze Jerzy Limon (Gdańsk: słowo/obraz terytoria, 1999).

24 Jerzy Limon, "Teatr musi dbać, byśmy nie zginęli w pustosłowiu”, Dziennik. Gazeta Prawna Online, 25 lutego 2020, https:// kultura.gazetaprawna.pl/artykuly/1455392,prof-jerzy-limon-nagroda-im-gieysztora-teatr-szekspirowski-gdansk.htm
} 
miasta. Odwiedzający teatr przechodzą z szarej codzienności do innego świata. Antracytowa, niemal czarna bryła, której fasada nawiązuje do gdańskiego gotyku, kryje w sobie lekką, wyłożoną drewnem scenę, audytorium, biura i sale wykładowe. Wnętrze teatru, przestronne i lśniąco białe, wypełnia światło. Sklepienie nad audytorium przypomina rozgwieżdżony strop katedry oliwskiej. Budynek teatru jest jak szkatuła $\mathrm{z}$ kosztownościami. Można ją otworzyć, dach teatru bowiem unosi bezszelestnie specjalna maszyneria. Pozwala to widzom doświadczyć prawdziwej magii teatru i potęguje niezapomniane wrażenia ze spektaklu. Kto wie, może w niektóre takie pogodne dni nawet Wielka Niedźwiedzica opisana w powieści Profesora odkłada na bok swoją zaczarowaną arfę, by spoglądać z góry na to, co dzieje się na scenie.

W 2016, w czterechsetną rocznicę śmierci Shakespeare’a ulicami miasta przeszła procesja czterystu płaczek, a o niezwykłym sposobie upamiętnienia dramatopisarza donosiła prasa kulturalna całego świata. Spektakularne wydarzenia przyciągają tłumy gdańszczan i turystów. Teatr zawsze tętni życiem: gdy nie goszczą w nim aktorzy, staje się domem muzyki, od kameralnych koncertów muzyki dawnej po ciężkie i ostre brzmienia heavy-metalu, niczym „wściekłość i wrzask” z żałobnego monologu Makbeta. Otwarty dla wszystkich, służy również celom edukacyjnym. We współpracy z założoną przez Limona Fundacją Gdański Teatr Szekspirowski proponuje warsztaty i wykłady dla uczniów i nauczycieli, edukatorów, seniorów, niepełnosprawnych; organizowane są sesje i spotkania naukowe. Akademicy, artyści teatru, krytycy dzielą się swoimi refleksjami z szeroką publicznością. W 2017 Profesor zorganizował w Gdańsku międzynarodowy Kongres Szekspirowski pod auspicjami European Shakespeare Research Association, który stał się znakomitą okazją do połączenia rozmowy o Shakespearze z festiwalem. Naukowcy z całego świata mogli nie tylko dyskutować na temat sposobów odczytywania dzieł Shakespeare’a, ale także wspólnie oglądać na scenie jego dramaty. Było to niezapomniane przeżycie. Uczestnicy konferencji mieli między innymi okazję wysłuchać wykładu wybitnego reżysera teatralnego Luka Percevala. Takie inicjatywy umożliwiały dialog dwóch światów. Jerzy Limon połączył akademicką refleksję z praktyką teatralną.

Pisząc ten tekst, wielokrotnie rozmawialiśmy o naszych spotkaniach i rozmowach $\mathrm{z}$ Profesorem. W pewnym momencie przywołaliśmy wyprawę na kongres w Pizie. Uwerturą do wielkiej przygody był wspólny lot z Monachium, który przeciągnął się z powodu bardzo gęstej mgły w Pizie (już wtedy musiały działać jakieś siły wyższe, bo atmosferyczne anomalie rzadko paraliżują tamtejsze lotnisko). Nasz samolot skierowano do Florencji, więc na miejsce dotarliśmy dopiero w środku nocy, lecz w iście szampańskich nastrojach, dzięki żartom i anegdotom Limona gotowi na dalsze przygody. Gdy więc organizatorzy przeoczyli fakt, że kilkadziesiąt kilometrów od Pizy, w Pontederze, wystawiano właśnie słynny Sen nocy letniej w reżyserii Oskarasa Koršunovasa, Profesor z figlarnym błyskiem w oku zaproponował wagary z Shakespeareem w porze uroczystej kolacji. Propozycja była podawana z ust do ust „zaufanym” delegatom. Chętnych szybko przybywało, 


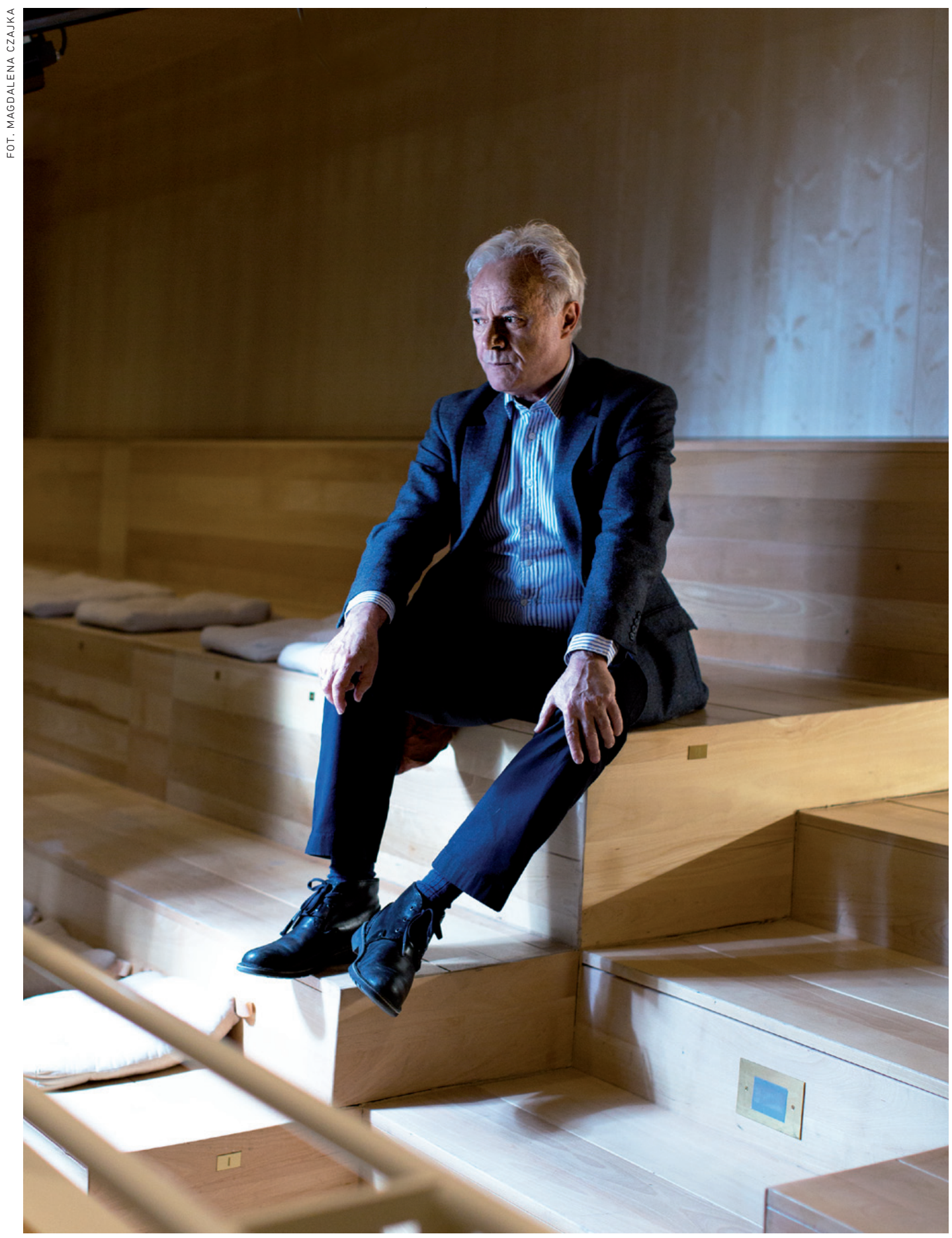

Jerzy Limon na widowni Gdańskiego Teatru Szekspirowskiego 
lecz dzięki nazwisku przywódcy tajnej wyprawy, który zapowiedział nasz przyjazd do Pontedery, biletów na spektakl starczyło dla wszystkich. Śniąc na jawie, po magicznym przedstawieniu powędrowaliśmy jeszcze na wspólny posiłek i w malutkiej restauracji wypełnionej wielojęzycznym tłumem uczestników kongresu wznosiliśmy radosne toasty na cześć Shakespeare’a, Jerzego i magii teatru. Gdy wieść o naszej wyprawie się rozeszła, tych, którzy zostali na oficjalnym bankiecie, brała zazdrość. A my, już w mniejszym gronie, po zakończeniu obrad wróciliśmy do Pontedery na zwiedzanie centrum Grotowskiego i spotkanie z jego ówczesnym dyrektorem, przyjacielem Profesora.

Działalność naukowa i kulturalna Jerzego Limona była wielokrotnie doceniana i nagradzana. Z rąk królowej Elżbiety II otrzymał Order Imperium Brytyjskiego, był laureatem Nagrody Jerzmanowskich, Nagrody im. Aleksandra Gieysztora, w Stratfordzie odebrał Pragnell Shakespeare Award. To ostatnie wyróżnienie, przyznawane nie tylko najwybitniejszym znawcom dzieł Mistrza ze Stratfordu, lecz także wielkim osobowościom teatru - wśród laureatów wymienić można choćby tak wspaniałych aktorów szekspirowskich jak Judith Dench i Kennetha Branagha - otrzymał jako pierwszy cudzoziemiec. Wyjaśnienie to powinniśmy opatrzyć jednak komentarzem: Profesor na pewno nie był „cudzoziemcem” w ponadczasowym uniwersum zaludnionym przez szekspirowskich monarchów, kupców, wesołe kumoszki, romantycznych kochanków, wędrownych aktorów i dobrodusznych rzemieślników. Był jednym z wielkich książąt tego świata. Inspirował, pociągał i rozbudzał ciekawość; wydobywał z każdego to, co najlepsze.

Pustki po Profesorze Limonie nie można zapełnić, ona pozostanie na zawsze. Odszedł wybitny naukowiec, człowiek kultury i teatru. Nie napisze już kolejnej książki o Shakespearze, nie opowie barwnie o teatrze i epoce elżbietańskiej, nie zorganizuje i nie otworzy kolejnego Festiwalu Szekspirowskiego, nie... Musimy urwać to zdanie. Trudno o tej stracie myśleć, jeszcze trudniej mówić, pogodzić się z nią niepodobna. Może jedyne, co w takiej chwili ma sens, to wyrazić Profesorowi głęboką wdzięczność w imieniu wszystkich, którzy mieli szczęście go spotkać. Dziękujemy za otwartość, mądrość, wielkoduszność.

\section{Bibliografia}

Limon, Jerzy. Brzmienia czasu: O aktorstwie i mowie scenicznej. Gdańsk: słowo/obraz terytoria, 2011.

Limon, Jerzy. Dangerous Matter: English Drama and Politics in 1623-1624. Cambridge: Cambridge University Press, 1986.

Limon, Jerzy. Gdański teatr „elżbietański”. Wrocław: Zakład Narodowy im. Ossolińskich, 1989.

Limon, Jerzy. Gentlemen of a Company: English Players in Central and Eastern Europe 1590-1660. Cambridge: Cambridge University Press, 1985. 
Limon, Jerzy. Między niebem a sceną: Przestrzeń i czas w teatrze. Gdańsk: słowo/obraz terytoria, 2002.

Limon, Jerzy. Obroty przestrzeni: Teatr telewizji - próba ujęcia teoretycznego. Gdańsk: słowo/obraz terytoria, 2008.

Limon, Jerzy. Piąty wymiar teatru. Gdańsk: słowo/obraz terytoria, 2006.

Limon, Jerzy. „Przypuszczalne związki teatru gdańskiej «Szkoły Fechtunku» z teatrem «Fortune» w Londynie”, Pamiętnik Teatralny 26, z. 1 (1977): 29-39.

Limon, Jerzy. Szekspir bez cenzury: Erotyczny żart na scenie elżbietańskiej. Gdańsk: Fundacja Terytoria Książki, 2018.

Limon, Jerzy. The Chemistry of the Theatre: Performativity of Time. New York: Palgrave Macmillian, 2010.

Limon, Jerzy. The Masque of Stuart Culture. Newark: University of Delaware Press, 1990.

Limon, Jerzy. Trzy teatry: Scena, telewizja, radio. Gdańsk: słowo/obraz terytoria, 2003.

Abstrakt

\section{Magia teatru: Wspomnienie o Profesorze Jerzym Limonie}

Prof. dr hab. Jerzy Limon był światowej sławy naukowcem, wybitnym znawcą Shakespeare’a i literatury angielskiej, teoretykiem teatru. Był także pisarzem oraz tłumaczem. Związany z Gdańskiem - wykładał i wychował pokolenia anglistów i teatrologów na Uniwersytecie Gdańskim, w Gdańsku zrealizował dzieło swojego życia: doprowadził do powstania Gdańskiego Teatru Szekspirowskiego w miejscu dawnej Szkoły Fechtunku. Tutaj też przez ponad dwadzieścia lat gościł teatry z całego świata w ramach międzynarodowego Festiwalu Szekspirowskiego.

\section{Słowa kluczowe}

Jerzy Limon, szekspirologia, teatrologia, Gdański Teatr Szekspirowski, Festiwal Szekspirowski

\section{Abstract}

\section{The Magic of the Theater: Remembering Professor Jerzy Limon}

Professor Jerzy Limon was a world-renowned scholar, expert on Shakespeare and English literature, as well as theater theorist. He was also a writer and translator. His professional career is linked with Gdańsk: he taught English literature and theatre at the University of Gdańsk; it was in Gdańsk that he had the Gdańsk Shakespeare Theatre built in the place where the Fencing School, housing an Elizabethan stage, once stood. Jerzy Limon created and supervised the Gdańsk Shakespeare Festival for over 20 years, which presented productions from all over the world.

\section{Keywords}

Jerzy Limon, Shakespeare studies, theater studies, Gdańsk Shakespeare Theater, Gdańsk Shakespeare Festival 


\section{JACEK FABISZAK}

dr hab., profesor na Wydziale Anglistyki Uniwersytetu im. Adama Mickiewicza w Poznaniu, kierownik Zakładu Badań nad Tekstami Kultury. Prezes Polskiego Towarzystwa Szekspirowskiego. Zajmuje się teatrem i dramatem renesansowej Anglii, bada dzieła Shakespeare'a i Marlowe'a oraz ich filmowe i teatralne adaptacje.

\section{MAŁGORZATA GRZEGORZEWSKA}

prof. dr hab., anglistka i szekspirolog, pracuje w Instytucie Anglistyki (w Zakładzie Literatury Brytyjskiej) na Wydziale Neofilologii i na Wydziale „Artes Liberales” Uniwersytetu Warszawskiego. Autorka publikacji o dramacie elżbietańskim i poezji metafizycznej. Zajmuje się związkami pomiędzy literaturą i filozofią. 